\title{
Avaliação dos impactos socioambientais urbanos: o descarte incorreto dos resíduos e atividade de conscientização ambiental na cidade de Apodi - RN \\ assessment of urban environmental impacts: improper waste disposal and environmental awareness activity in Apodi city
}

\author{
Adriano Erik Reinaldo de Morais*, Plinio Tavares Barbosa, Leonardo Alcântara Alves \\ ${ }^{1}$ Instituto Federal de Educação, Ciência e Tecnologia do Rio Grande do Norte, RN, Brasil
}

\begin{abstract}
Resumo
O surgimento de novas tecnologias resulta no crescimento do número de indústrias e aumento populacional nos centros urbanos. Atrelado a esse crescimento surge a problemática dos resíduos, estes que se transformaram em graves problemas urbanos, muitas vezes, com um gerenciamento oneroso e complexo. Devido à escassez de áreas para deposição, os resíduos estão ligados diretamente à qualidade de vida de uma sociedade. A quantidade de resíduos produzida por uma população depende de uma série de fatores, como renda, época do ano, modo de vida. Mesmo considerada uma cidade de pequeno porte, Apodi apresenta um crescimento significativo em sua produção de resíduos domésticos e, não havendo um destino correto para os mesmos, surge uma série de problemas socioambientais, tais como: estéticos, saúde e ambiental na cidade. As discussões sobre essa problemática procura responder quais os possíveis impactos socioambientais causados por esses resíduos domésticos e deficiências de instrumentos de saneamento ambiental na população afetada. Contudo, o presente trabalho tem como objetivo principal propor estudos de conscientização dos impactos socioambientais oriundos do descarte incorreto dos resíduos domésticos na cidade de Apodi - RN, através de pesquisas realizadas e a identificação dos problemas enfrentados pela população da cidade.
\end{abstract}

Palavras-chave: Centros Urbanos. Resíduos Domésticos. Conscientização. Impactos Ambientais.

\begin{abstract}
The emergence of new technologies results in the growth of industries and population growth in urban centers. Coupled to this growth comes the problem of waste, these that turned into serious urban problems, often with a costly and complex management. Due to the shortage of areas for disposal, waste is directly linked to the quality of life of a society. The amount of waste produced by a population depends on a number of factors such as income, time of year, way of life. Even considered a small town, Apodi presents a significant growth in its production of household waste, and there was a correct destination for them, comes a series of environmental problems such as: aesthetic, health and environment in the city. Discussions on this issue seeks to answer what the possible environmental impacts caused by these deficiencies household waste and environmental sanitation instruments in the affected population. However, this paper aims to propose awareness studies of environmental impacts arising from the incorrect disposal of household waste in the city of Apodi - RN, through research carried out and to identify the problems faced by the population of the city.
\end{abstract}

Keywords: Urban. Domestic Waste. Awareness. Environmental Impacts.

* adriano.erik@hotmail.com

Recebido: 09/10/14 Aceito: 29/02/16 


\section{Introdução}

Nas últimas décadas, observa-se que o acúmulo de resíduos, resultado do aumento da produção tecnológica e industrial, transformaram-se em graves problemas urbanos, com um gerenciamento oneroso e complexo, principalmente devido à escassez de áreas para deposição, altos custos sociais no tocante ao seu tratamento, bem como problemas de saneamento público e contaminação ambiental (FILHO; GURGEL; REINALDO, 2011).

A dinâmica de intervenção e urbanização do espaço pela sociedade atual resultou em várias mudanças dos ecossistemas naturais do planeta. Junto a essas práticas e influências de uso desordenado dos ecossistemas terrestres bem como o aumento populacional provocou a necessidade de novas formas de consumo na sociedade, que vem sendo estimulada pelo setor industrial, principal responsável pela escassez de seus recursos naturais (MELO et al., 2012).

Observa-se que a quantidade de resíduos produzida por uma população depende de uma série de fatores, como renda, época do ano, modo de vida, movimento da população nos períodos de férias e fins de semana e novos métodos de acondicionamento de mercadorias, com a tendência mais recente de utilização de embalagens não retornáveis (MOURA; SOUZA; SILVA, 2011).

Os resíduos sólidos urbanos (RSU) se caracterizam como importantes agentes causadores de degradação do ambiente urbano e natural e constituem-se meios para o desenvolvimento e proliferação de vetores tais como ratos, baratas, mosquitos entre outros, que em contato com o lixo transmitem doenças infecciosas (FILHO; SOBREIRA, 2007).

Segundo Flores (2010), resíduos sólidos são "todos os restos sólidos ou semissólidos das atividades humanas ou não humanas que, embora possam não apresentar utilidade para a atividade, fim de onde foram gerados, podem virar insumos para outras atividades". Podemos considerar ainda resíduo sólido como qualquer material restante de uma ação ou processo produtivo.

Carvalho (2008) classifica estes resíduos sólidos em dois grandes grupos, os biodegradáveis e os que não se decompõem biologicamente. Os resíduos não degradáveis ou considerados recicláveis têm a vantagem de afetar menos os processos de destinação sanitária, mas pelo seu efeito acumulativo causam transtornos no acondicionamento e reduzem vida útil nos aterros, também com seu o acúmulo excessivo nos centros urbanos, causa transtornos sociais e ambientais. Uma das maneiras adotadas para o melhor gerenciamento do lixo doméstico é a coleta seletiva do mesmo, ao facilitar a reciclagem, reduz o seu acúmulo e poluição, além de agregar alguma renda ao processo.

A problematização gerada pelo lixo é de difícil solução e a maior parte das cidades brasileiras apresenta um serviço de coleta que não prevê a segregação dos resíduos na fonte (IBGE, 2006). Nessas cidades é comum observarmos hábitos de disposição final inadequados de lixo. Materiais sem utilidade se amontoam indiscriminadamente e desordenadamente, muitas vezes em locais indevidos como lotes baldios, margens de estradas, fundos de vale e margens de lagos e rios (MUCELIN; BELLINI, 2008).

No Brasil tem-se uma produção de 241.614 toneladas de lixo por dia, onde $76 \%$ são depositados em lixões a céu aberto, 13\% em aterros controlados, $10 \%$ em usinas de reciclagem e 1\% são incinerados. Do total do lixo urbano, $60 \%$ são formados por resíduos orgânicos que podem se transformar em excelentes fontes de nutrientes para as plantas (EMBRAPA, 2005).

Mucelin e Bellini (2008) descrevem ainda que o lixo doméstico no Brasil é composto por: $65 \%$ de matéria orgânica; $25 \%$ de papel; $4 \%$ de metal; $3 \%$ de vidro e $3 \%$ de plástico. Apesar de atender a legislação específica de cada município, o lixo comercial e o domiciliar são de responsabilidade das prefeituras, enquanto os demais são de responsabilidade do próprio gerador.

Com os diversos fatores que contribuem para o aumento do lixo, deparamos com fatores causados pelo tratamento incorreto desses resíduos. Simplesmente depositado nos "lixões", tem um enorme potencial de contaminação do solo, da água e do ar, principalmente os de origem hospitalar ou industrial. Encontramos atualmente diversas formas e técnicas de tratamento do lixo disponíveis que amenizam os seus efeitos nocivos através de processos de incineração, desinfecção ou esterilização. 
Marques (2005) aponta que os impactos causados no ambiente urbano, principalmente na periferia, como a poluição do solo, decorrem, sobretudo, pelo acúmulo inadequado de resíduos sólidos que, na sua maioria, são lançados nos logradouros públicos e em lixões, constituindo-se uma verdadeira ameaça ao meio ambiente, pois não recebem tratamento, causando a proliferação de insetos, roedores e aves que se alimentam da matéria orgânica que ali é depositada.

Frente a esses parâmetros, as cidades apresentam-se, muitas vezes, carentes de infraestrutura básica, fruto da política de utilização do espaço ao longo do tempo. Dentre os graves problemas ambientais reunidos nas periferias das cidades, podemos destacar a falta de pavimentação adequada nas ruas e saneamento básico, falta ou insuficiência de serviços de saúde, educação, transportes, recolhimento de lixo, segurança (MARQUES, 2005). Com isso, pode-se apontar que a qualidade de vida de uma população está diretamente relacionada com a infraestrutura urbana em que está inserida (CALIJURI, 2009).

Mesmo considerada uma cidade de pequeno porte, Apodi apresenta 34.777 habitantes e com uma área de $1.602 \mathrm{~km}^{2}$, tendo um crescimento significativo de sua população entre 1996 a 2000, (IBGE, 2007 e 2010). Crescimento este que vem acompanhado do aumento na produção de resíduos domésticos onde, não havendo um destino correto para os mesmos, surge uma série de problemas, tais como: estéticos, de saúde e ambientais.

De acordo com órgãos responsáveis, a limpeza urbana do município de Apodi é de responsabilidade da prefeitura municipal na qual é feita periodicamente, de forma convencional. $\mathrm{O}$ transporte dos resíduos da cidade é feito por caçambas basculantes e carros coletores de lixo, estes que tem como destino final o aterro sanitário que é gerenciado pela prefeitura. (IDEMA, Instituto de Desenvolvimento Sustentável e Meio Ambiente do RN/Prefeitura Municipal - Apodi RN, 2003).

“Em nota de informação ao IDEMA a prefeitura de Apodi relata existir coleta seletiva de seu lixo, este que quando reciclável é destinado a usinas de reciclagem, quando não reciclável é destinado ao aterro sanitário da cidade" (IDEMA, 2003).

Segundo pesquisas e relatos da população local, na atualidade a informação relatada acima não se encontra em vigor, visto também que não existe uma política social de conscientização no que diz respeito à coleta seletiva ou medidas que venham a minimizar esses problemas.

A discussão sobre a problemática socioambiental não se restringe só a cidade de Apodi, mas também aos grandes centros urbanos, já que se trata de uma temática que contempla saúde pública e coletiva. Na zona urbana de Apodi - RN, onde foi efetuada a pesquisa, percebe-se uma enorme carência de estudos dessa natureza. Logo, esta procura responde quais os possíveis impactos socioambientais causados por esses resíduos domésticos e deficiências de instrumentos de saneamento ambiental para a população da área. Com isso, o estudo visou propor a análise e conscientização dos impactos socioambientais oriundos do descarte incorreto dos resíduos domésticos na cidade de Apodi - RN.

\section{Metodologia}

O planejamento operacional deste estudo teve fundamentação em pesquisas realizadas na cidade de Apodi, tendo em vista vários aspectos observados, com foco nos impactos causados pelos descartes incorretos de resíduos domésticos da cidade.

\subsection{Avaliação do Aterro Sanitário de Apodi}

Inicialmente, foi realizado a avaliação do local onde são depositados diariamente os resíduos coletados na cidade, no intuito de constatar se existia um tratamento adequado para cada tipo de lixo produzido. A avaliação foi realizada in loco avaliando-se também a adequação das condições do Aterro. 


\subsection{Avaliação da comunidade e órgão gerenciador}

Dentro da análise do trabalho, realizou-se uma avaliação na Comunidade "Projeto Casulo", localizada nos arreadores do Aterro sanitário da Cidade. Para a realização da pesquisa e coleta de dados, trabalhou-se com a aplicação de um questionário, o qual foi aplicado às famílias da mesma. $\mathrm{O}$ questionário tinha como objetivo avaliar questões do tipo: transtornos causados pelo lixo, problemas de saúde, estética local e hábitos da população em gerenciar o seu próprio lixo, entre outros.

Além disso, outro questionário foi aplicado ao órgão responsável pelo gerenciamento dos resíduos domésticos produzidos no município. A análise buscou identificar como é gerenciado o lixo do município, a existência de políticas públicas voltadas à conscientização ambiental, dados quantitativos da produção de lixo na cidade, disposição de funcionários no gerenciamento desses resíduos e como se dá a disposição final do lixo no município.

\subsection{Palestras como atividade de conscientização ambiental}

Uma das metodologias empregadas neste trabalho foi a apresentação de palestras de conscientização na Escola Estadual Professor Antônio Dantas. Na mesma, inicialmente realizada com duas turmas de $3^{\circ}$ ano do ensino médio, foi explanada a problemática enfrentada no mundo atual, bem como na cidade de Apodi-RN, os impactos provocados pelo mau gerenciamento do lixo doméstico, entre outros.

Após a apresentação oral, abriu-se um momento de discussões, onde foram levantadas, juntamente com os alunos, pontos relevantes sobre o tema.

A turma foi dividida em grupos e, em seguida, cada grupo deveria expor a sua resposta sobre cada ponto posto em discussão, abrindo espaço para opiniões e sugestões dos outros grupos frente à resposta do mesmo.

\subsection{Panfletagem de conscientização na cidade de Apodi-RN}

Outra proposta do trabalho foi a realização de panfletagem nas escolas e na comunidade. Esta visava a conscientização de toda comunidade escolar, a partir da exposição de informações que podem ser adotadas a fim de minimizar os impactos provocados pelo lixo domiciliar, bem como apresentar algumas informações coletadas nas etapas anteriores no que diz respeito ao lixo produzido na cidade de Apodi.

A atividade foi realizada na Escola Estadual Professor Antônio Dantas, na Escola Estadual Professora Maria Zenilda Gama e também na Comunidade "Projeto Casulo" de maneira a atingir o público alvo do trabalho.

\section{Resultados e discussão}

A princípio, visitou-se o Aterro da cidade, percebendo-se diversos problemas com gerenciamento do lixo produzido em Apodi, sendo observada a presença de catadores de lixo no local que auxiliaram na visita. Pôde-se perceber que os dejetos depositados no local eram apenas queimados, não havendo qualquer tratamento por tipo ou característica do lixo.

Visualizou-se também o descarte de lixo hospitalar (Figura 1) da cidade, sendo que o mesmo, por apresentar grande capacidade de contaminação, exige um gerenciamento especial. Apesar disso, esses resíduos são depositados a céu aberto sem nenhuma forma de controle ou separação devida. 


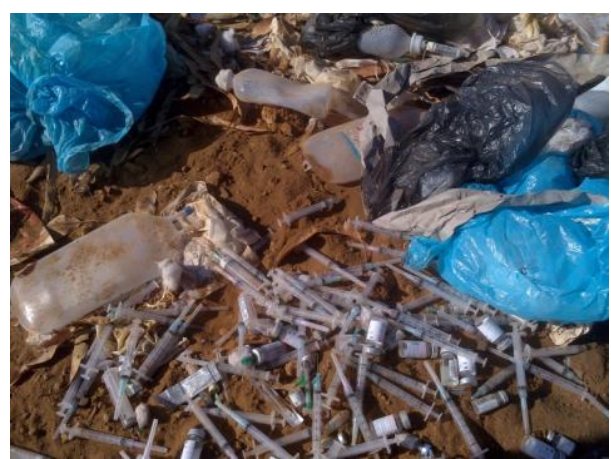

Figura 1 - Lixo hospitalar jogado a céu aberto

Fonte: Próprios autores

De acordo com relatos dos catadores, a cerca de 10 anos o local foi inaugurado com a função e denominação de Aterro Sanitário controlado. Entretanto, os catadores afirmam que apenas no período dos 2 anos iniciais a denominação e normas foram cumpridas, passando a ser utilizado como lixão a céu aberto nos anos seguintes.

\subsection{Avaliação da Comunidade "Projeto Casulo"}

A análise realizada na comunidade próxima ao Aterro da cidade mostrou que esta é composta por 17 famílias que em sua totalidade somam 59 moradores, dos quais foi alvo de nossa pesquisa de levantamento de dados e de opinião popular. No total foram entrevistadas 15 famílias, sendo feitas perguntas que relacionavam, principalmente, sua qualidade de vida frente os problemas provocados pela proximidade das residências com o Aterro.

Na primeira pergunta feita aos moradores pode-se confirmar que, de maneira contínua, vêm sofrendo transtornos por conta da má localização do lixo e da forma indevida como se dá destino final aos resíduos da cidade pesquisada. Perguntados se sofriam algum tipo de transtorno por conta do lixão, $100 \%$ afirmam sofrer com problemas variados, conforme destacado no Gráfico 1, a seguir.

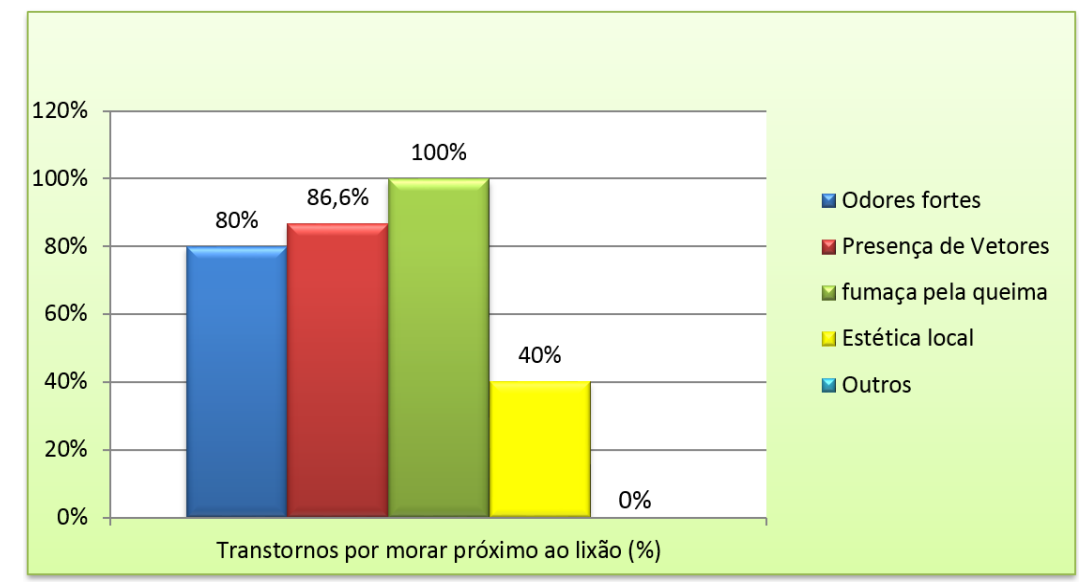

Gráfico 1 - Principais problemas provocados pelo Aterro aos moradores

Fonte: Próprios autores

Ainda de acordo com os relatos e dados coletados, pode-se perceber que entre suas classificações destaca-se principalmente a fumaça pela queima irregular dos resíduos lá depositados. Esta tem provocado graves problemas de saúde na comunidade tais como problemas respiratórios que comprometem a qualidade de vida do local.

Em seguida, foi questionado aos moradores de que forma eles tratavam o seu próprio lixo, de que maneira o mesmo era descartado. Os dados das respostas estão destacados no Gráfico 2, a seguir, que apresenta em números a relação das respostas coletadas. 


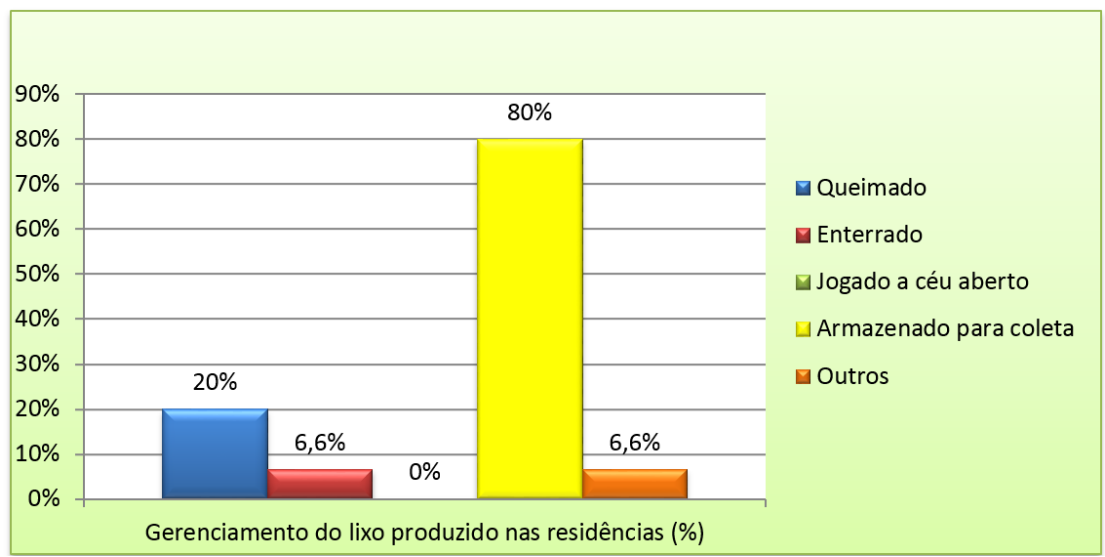

Gráfico 2 - Avaliação sobre a forma de descarte do lixo utilizado pelos moradores

Fonte: Próprios autores

Como pode-se ver através dos dados coletados, que em sua maior parte os moradores armazenam seus resíduos em locais apropriados. Locais estes disponibilizados pelos órgãos responsáveis pela limpeza e coleta dos resíduos urbanos do município. Importante destacar que dos $6,6 \%$ da coluna (outros) do gráfico, parte dos moradores separam alguns tipos de lixo e reutilizam ou vendem para reciclagem. Ainda de acordo com os moradores, essa coleta é feita em intervalos semanais, onde uma vez por semana um carro responsável pela coleta desses resíduos recolhe-os e são destinados ao lixão.

Quando perguntados, se tinham conhecimento do que se tratava a coleta seletiva dos resíduos, em sua totalidade $100 \%$ dos moradores responderam: Sim, que é de total conhecimento a forma de se separar o seu lixo de acordo com as classes e características básicas do lixo. Porém, perguntados se havia na comunidade implementação da coleta seletiva, $100 \%$ dos moradores responderam: Não, deixando claro que não há um cuidado acerca da separação do seu lixo. De acordo com os moradores a separação não é feita por falta de incentivo dos órgãos responsáveis pela coleta, tendo em vista que todo o lixo da cidade é descartado de maneira aleatória sem nenhum cuidado ou separação.

Para fins de informação, foi perguntada aos moradores quanto ao abastecimento de água de suas residências, qual era a fonte da água utilizada pelos moradores. As respostas estão ilustradas no Gráfico 3, a seguir:

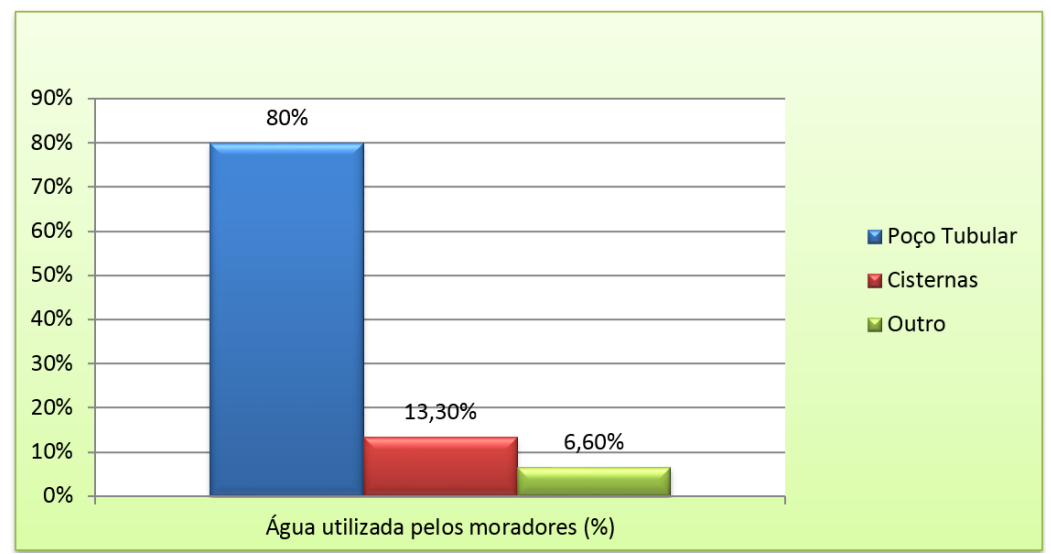

Gráfico 3 - Fonte de água da comunidade

Fonte: Próprios autores

Como pode-se observar, $80 \%$ da água consumida pela comunidade é proveniente de poço tubular e, quando perguntado sobre a localização do poço, foi informado que o mesmo era instalado a alguns quilômetros do Aterro. É importante ressaltar que nos 6,6\% do item (Outro), utilizam água proveniente de caminhões pipas que abastecem as suas residências. 
Ao serem questionados se nas residências eram tomadas medidas que contribuíssem para a redução da produção de resíduos, os moradores responderam de acordo com os dados apresentados no Gráfico 4 a seguir:

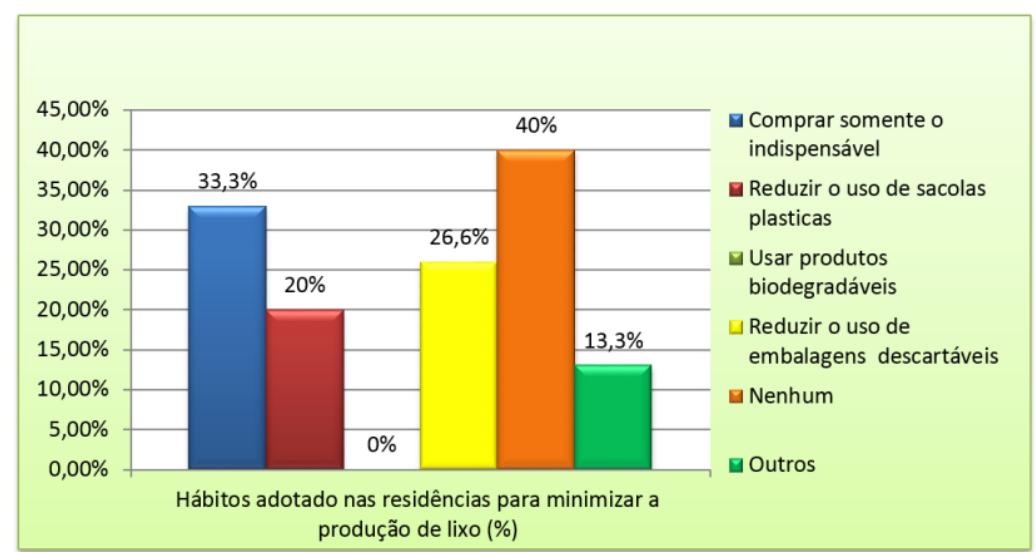

Gráfico 4 - Hábitos adotados pelos moradores para redução da produção de lixo

Fonte: Próprios autores

De acordo com os relatos dos moradores, em sua maioria, não costumam tomar nenhum tipo de medida para a redução da produção de seus resíduos, visto que a falta de incentivo e interesse por parte dos órgãos responsáveis comprometem essa criação de hábito, no que diz respeito à redução e conscientização.

Ao perguntar se existia alguma política de incentivo à preservação ambiental na comunidade, $100 \%$ dos moradores responderam sofrerem por falta de visibilidade por parte do órgão responsável. Relatos deixam claro que, dos problemas enfrentados pela comunidade, pouco é feito pelos responsáveis pela administração pública do município.

Ainda de acordo com relatos das famílias, 100\% dos mesmos responderam ter contraído alguma doença proveniente dos problemas provocados pelo Aterro. Tais como gripe, tosse, irritação nas vias nasais e visuais, bem como problemas respiratórios, problemas esses que afetam em sua grande maioria as crianças da comunidade.

Ao final do questionário, perguntou-se aos moradores se eles poderiam cita alguma sugestão para a resolução dos problemas presentes na comunidade. Em sua totalidade $100 \%$ dos moradores pediram a retirado do lixão da comunidade, fazendo com que a problemática enfrentada por eles viesse a ter fim, contribuindo para uma melhor qualidade de vida e tornando assim o ambiente mais saudável para se viver.

\subsection{Questionário aplicado à Secretaria Municipal de Obras e Urbanismos do município} de Apodi-RN

O questionário aplicado à Secretaria Municipal de Urbanismos de Apodi, foi de suma importância para o entendimento de como o trabalho de coleta é realizado na cidade. Em questionário, a Secretaria nos informou que o gerenciamento de lixo do município é realizado diariamente, no qual a coleta é dividida por zonas (Leste e Oeste da cidade), efetuada por dois caminhões coletores, nos dias de segunda a sábado contemplando as áreas residenciais, comerciais e industriais da cidade.

Quando questionado se existia no município políticas públicas sobre o manuseio e descarte correto do lixo doméstico, foi relatado que, no presente momento, não existia em vigor nenhuma política que contemplasse a temática abordada pelo questionário. Porém, adiantou a implementação de um projeto que englobará as áreas rurais e urbana do município, que intitula-se como: "Nada se Perde Tudo se Recicla". 
A Secretaria informou ainda que a cidade produz cerca de 30 toneladas de resíduos sólidos por dia, isso leva a perceber que a temática em questão é de suma importância para a qualidade de vida da população, visto que a quantidade de lixo produzido é significativamente grande.

Para lidar com o gerenciamento muitas vezes oneroso destes resíduos, observou-se que a secretaria dispõem de 45 funcionários, divididos em quatro equipes: Varrição, Coletores, Podadores da arborização e coletores de lixo específicos (hospitalar e industrial). Também foi esclarecido que não existe uma coleta seletiva por parte dos funcionários, devido à disposição final do lixo ser sempre o mesmo local (Aterro do município), que nele não há nenhum tipo de separação por categoria de lixo, sendo assim inviável a sua separação. Vale ressaltar que a disposição de lixo em Aterros controlados é necessária a prévia separação do mesmo para tratamento futuro.

Foi informado também, junto à Secretaria, que os problemas relacionados aos descartes incorretos no Aterro da cidade terão que ser solucionados. Tendo em vista o decreto 7.404/2010 que regulamenta a política nacional de resíduos sólidos (Lei 12. 305 de 2 de agosto de 2010), o que estabelece normas para a execução dessa política nacional. A qual exige que os municípios brasileiros acabem com seus lixões a céu aberto até 2014, caso não sendo cumprido, responderão por crime ambiental.

\subsection{Palestra na Escola Estadual Professor Antônio Dantas}

A princípio procurou-se as direções das escolas trabalhadas, no intuito de desenvolver o projeto nas mesmas. Demostrado interesse pelos diretores, direcionou-se a uma das professoras da Escola Estadual Professor Antônio Dantas, que disponibilizou duas de suas turmas para que pudessem ser desenvolvidas as atividades.

$\mathrm{Na}$ escola foi trabalhado com a apresentação de palestra de conscientização acerca da problemática do lixo, como pode ser visto nas figuras 2 , a seguir:

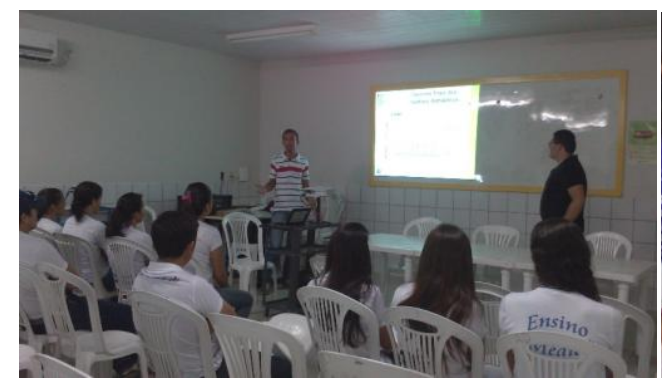

Figura 2 - Palestra na Escola Antônio Dantas Fonte: Próprios autores

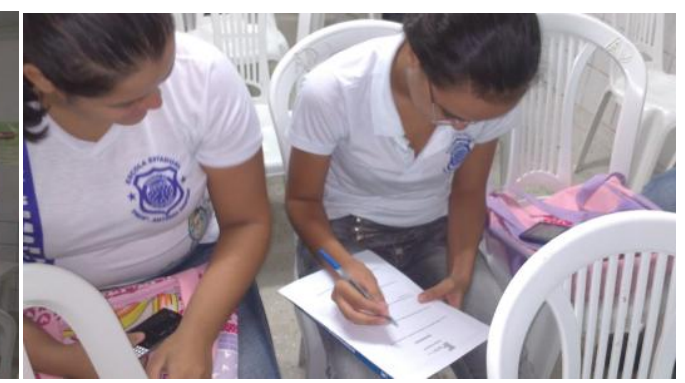

Na palestra abordou-se temas como: Problemas do lixo domiciliar na cidade de Apodi, Composição do lixo domiciliar, o que pode-se fazer para reduzir a produção entre outros pontos que atraiu bastante a atenção dos alunos que assistiam a mesma.

Ao final da explanação a turma foi dividida em 5 grupos, dos quais, cada grupo ficaria encarregado de responder uma questão sobre a problemática proposta nas palestras. O grupo deveria discutir entre eles e formularem uma resposta, que em seguida seria exposta para os demais colegas (Figura 3). 


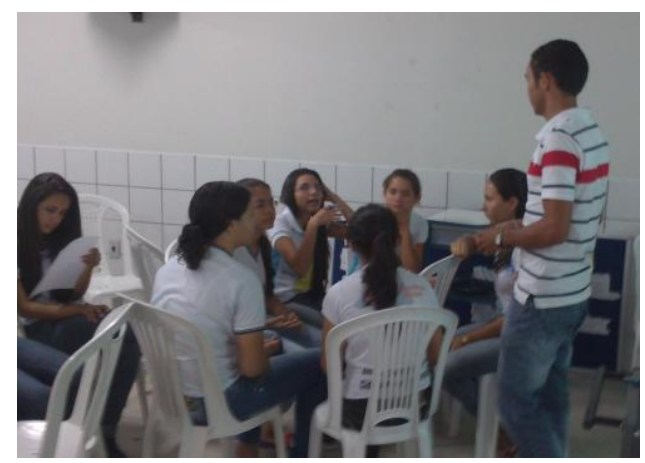

Figura 3 - Discussão entre grupos de trabalho

Fonte: Próprios autores

Os alunos demostraram em suas respostas que fixaram bem os assuntos abordados na palestra, com respostas concisas e diretas. A seguir, a descrição de algumas respostas dadas pelos alunos após a apresentação da palestra.

Quando questionado sobre que medidas podem ser tomadas para resolver a problemática? O grupo chegou à seguinte conclusão: "Conscientizar as pessoas mostrando os problemas que isso pode acarretar, buscar ações e movimentos para tentar diminuir esse problema e ter apoio de governantes e da população para resolver os problemas".

Já quando questionado "de que maneira podemos conscientizar a população sobre os problemas do lixo doméstico?" O grupo respondeu: "Através de campanhas, conscientizar a população a separar o lixo corretamente, cobrar dos órgãos público, a forma de tratar o lixo no lixão para que acabem com a poluiçãa".

Por fim quando questionado sobre "que benefícios podemos conseguir com a implementação dos métodos?" O grupo explanou: "Menos poluição, uma cidade mais limpa, sem riscos de contaminar o ar, o solo que desde poluído pode demorar anos para se recompor como as plantas e também não causara doenças nos seres humanos onde uma vez prejudicado pode perder a vida. Devemos repensar melhor e fazermos mais para o meio ambiente."

\subsection{Panfletagem nas Escolas Estaduais e Comunidade}

Uma das metodologias aplicadas no projeto foi a panfletagem, na qual foi desenvolvida nas escolas durante o horário do intervalo das aulas, sendo mais fácil a divulgação das informações de maneira a atingir o maior número de alunos possível (Figura 4).

No panfleto, estavam apresentados alguns resultados do projeto que retratam a realidade da problemática do lixo na cidade da Apodi, bem como medidas que podem ser tomadas pela população em seu cotidiano, assim como sensibilizar a comunidade escolar desse tema tão importante no mundo contemporâneo.
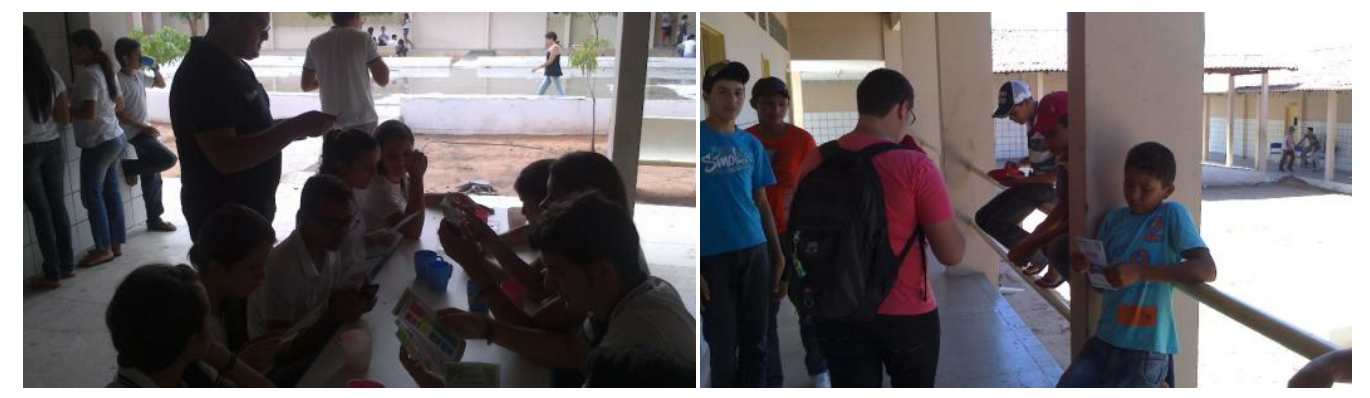

Figura 4 - Panfletagem nas Escolas Estaduais de Apodi - RN

Fonte: Próprios autores

Com isso esperou-se conscientizar a classe estudantil dos problemas e medidas que podem ser tomadas a fim de se minimizar os impactos provocados pelos resíduos domésticos.

É importante salientar que em ambas as escolas na qual o projeto foi desenvolvido existiam a coleta seletiva dos resíduos produzidos. No entanto, segundo informações dos professores e 
funcionários das escolas, muitos alunos não a utiliza de maneira correta, sendo assim de fundamental importância a implementação de projetos de conscientização nas escolas.

Além das Escolas Estaduais, um outro ponto de pesquisa e conscientização foi realizado na comunidade "Projeto Casulo" que é situada próximo ao lixão da cidade de Apodi-RN.

A panfletagem foi desenvolvida de maneira a atingir o maior número de moradores possíveis da comunidade como pode ser visto na Figura 5, a seguir.

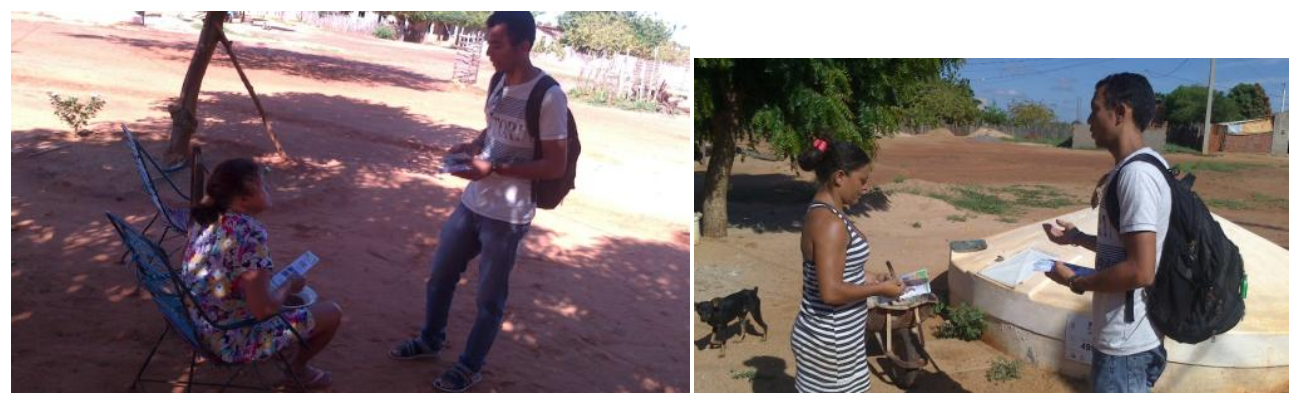

Figura 5 - Panfletagem na Comunidade "Projeto Casulo"

Fonte: Próprios autores

Com isso espera-se uma conscientização efetiva nos moradores, e que algumas medidas como a reutilização de materiais presentes no lixo, reciclagem de parte dos resíduos produzidos em suas residências possa ser adotados não só pelos moradores da comunidade mais todos as pessoas da cidade de Apodi, visto que estes são os principais responsáveis pela grande produção de lixo.

Importante salientar que, durante o trabalho, descobriu-se que já existe uma pequena iniciativa por parte de duas moradoras da comunidade em reciclar parte do lixo que é depositado nas proximidades da comunidade.

Através de atitudes simples como dessas pessoas que possam vir a se tornar exemplos a serem seguidos, pode ser minimizado grande parte dos problemas causados pelo lixo doméstico.

\section{Considerações finais}

Ao final das pesquisas pode-se concluir que o aterro acerca de aproximadamente 8 anos deixou de ser de fato, um aterro, e veio a se tornar um lixão a céu aberto por não apresentar nenhuma forma de tratamentos dos dejetos depositados no local.

No que diz respeito à comunidade do "Projeto Casulo", é notório as reclamações por parte dos moradores, que tanto tem sido prejudicados com a presença e má administração deste Aterro. As principais insatisfações dos moradores é justamente a proximidade do mesmo com as residências, bem como os problemas que o mesmo provoca a seus familiares, como fumaça proveniente da queima irregular do lixo, a presença de vetores, animais que atuam como transmissores de doenças, principalmente para as crianças da comunidade, além de prejudicar e comprometer a estética e a qualidade de vida das 17 famílias que lá residem.

Já no que desrespeito ao órgão que é responsável pelo gerenciamento de resíduos no município é de total conhecimento essa problemática, porém, os mesmos não são solucionados devido a uma série de fatores que dificultam a resolução da problemática, tais como: costumes e hábitos da sociedade bem como problemas administrativos que vem ao longo do tempo sendo repassados de gestão para gestão do município.

Contudo, pode-se observar que os objetivos pertinentes ao projeto desenvolvido foram alcançados. Após diversas atividades desenvolvidas no decorrer do projeto a finalidade principal, que era de trabalhar com uma linha de pesquisa frente a problemática do lixo domiciliar na cidade de Apodi, e com isso desenvolver metodologias que pudessem informar, conscientizar a comunidade com dados coletados tanto na comunidade como nos órgãos responsáveis pelo gerenciamento do lixo no município, foram bem sucedidos. 
Dessa forma, espera-se ter contribuído para uma reflexão deste tema tão polêmico no mundo contemporâneo e fazer com que pequenas atitudes possam ser tomadas pela comunidade. Com a conscientização da comunidade escolar formar cidadãos mais conscientes e mais adeptos da questão ambiental.

\section{Referências}

CALIJURI, M. L. Estudo de indicadores de saúde ambiental e de saneamento em cidade do Norte do Brasil. Revista de Engenharia Sanitária Ambiental, Rio de Janeiro, v. 14, no 1, 2009.

CÂMARA, S.C; AFONSO, J. C. Simulação de Intemperismo de Pilhas Zinco-Carbono e Alcalinas. Revista Química Nova, v. 35 p. 83, 2012.

CARVALHO, F. Tratamento do lixo é um problema de todos, Revista eletrônica UAI, 2008.

EMBRAPA - Empresa Brasileira de Pesquisa Agropecuária, Dados da produção de lixo no Brasil, 2005.

FLORES, G. N. Possibilidade Jurídica da Gestão integrada de resíduos sólidos urbanos através de consórcios públicos, Revista eletrônica Direito e política, v. 5, nํำ1, 2010.

FILHO, J. F. P; SOBREIRA, F. G. Desempenho operacional e ambiental de unidades de reciclagem e disposição final de resíduos sólidos domésticos, financiados pelo ICMS, 2007.

IBGE - Instituto Brasileiro de Geografia e Estatística, 2006.

FILHO, J. L.; GURGEL, L. L.; REINALDO, E. D. Aspectos de saneamento ambiental da baixa do CAIC no bairro lagoa seca na cidade de Apodi-RN. Revista Científica do IFAL, v. 1, no 2, 2011.

IBGE - Instituto Brasileiro de Geografia e Estatística, Dados geográficos da cidade de Apodi - RN, 2007 e 2010

IDEMA - Instituto de Desenvolvimento Sustentável e Meio Ambiente, Prefeitura municipal de Apodi - RN, 2003.

MOURA, J. M; SOUZA, V.; SILVA, J. A. Gestão de resíduos sólidos domiciliares em Cuiabá: gerenciamento. IBEAS - Instituto Brasileiro de Estudos Ambientais, 2009.

MARQUES, J. R. Meio ambiente urbano. Rio de Janeiro: Forense Universitária, 2005.

MELO, A. A.; MELO, G. K. R. M. M.; MELO, V. L. A.; AZEVEDO, K. C. A. V.; LIRA, W. S. Territorialização da usina de compostagem de resíduos sólidos urbanos da cidade de esperança PB e sua contribuição socioambiental, Revista eletrônica UEPB, v.13, nำ1, 2012.

MUCELIN, C. A.; BELLINI, M. Lixo e Impactos Ambientais Perceptíveis no Ecossistema Urbano. Sociedade \& Natureza, v. 20 ํํำ 2008. 